\title{
Estado de la cuestión de la Publicidad Institucional en España (2006-2012)
} Status of Institutional Advertising in Spain (2006-2012)

\author{
Esther Martínez Pastor (España) \\ Universidad Rey Juan Carlos \\ esther.martinez.pastor@uric.es
}

\section{Resumen}

Este trabajo pretende mostrar el estado de la cuestión de la Publicidad Institucional en España. Para ello, primero se abordará la publicidad institucional como parte de la comunicación institucional y de la comunicación pública. Una vez encuadrada esta modalidad publicitaria se describirá su evolución en España partiendo de la aproximación a la

\section{Abstract}

This article aims to show the status of Institutional Advertising in Spain. In order to do this, we consider institutional advertising as part of institutional and public communication. Once this modality of advertising is framed, we describe its evolution in Spain from an approximation to institutional advertising, its recent legal framework and we also analyze the investment, number of campaigns, and

$\begin{array}{lrl}\text { RECIBIDO: } & 2 \text { de septiembre de } 2015 & \text { PARA CITAR ESTE ARtícUlo / TO CITE THIS ARTICle } \\ \text { EVAlUADO: } & 21 \text { de septiembre de } 2015 & \text { Martínez, E. (2015). Estado de la cuestión de la } \\ \text { ACEPTADO: } & 19 \text { de octubre de } 2015 & \text { Publicidad Institucional en España (2006-2012). } \\ & & \text { Poliantea, 1 1 (21). pp. 105-128. }\end{array}$

POLIANTEA | P. 105-128 | VOLUMEN XI | Número 21 | JULIO-DiCiembre 2015 
- Estado de la cuestión de la Publicidad Institucional en España (2006-2012) - Esther Martínez Pastor

publicidad institucional, su reciente marco jurídico, así como se analizará la inversión, el número de campañas y los medios seleccionados por la Administración Pública durante el periodo 2006-2012.

Palabras clave: publicidad institucional, comunicación institucional, comunicación pública, regulación jurídica, inversión. media selected by the Public Administration from 2006 to 2012.

Keywords: Institutional advertising, institutional communication, public communication, legal regulation, investment. 


\section{Comunicación pública, comunicación institucional y publicidad institucional}

La comunicación pública, en sentido amplio, comprende todas las actividades desarrolladas por la Administración en los sectores de la información y de la comunicación (Tornos \& Galán, 2000). En sentido estricto, se caracteriza porque, de un lado, el sujeto activo de la comunicación es un poder público y su destinatario es el ciudadano $y$, por otro lado, el mensaje es relativo a asuntos públicos y de interés general (Tornos \& Galán, 2000; Salerno, 2003). Esto indica que la comunicación pública puede ser información y comunicación de carácter institucional. Nos centraremos en este binomio información- comunicación, dejando de lado las disquisiciones acerca de lo que es la comunicación pública ni la opinión pública, tema tratado por numerosos autores, como Habermas (1999) o Lippmam (2003), sino que solamente aludimos al origen de la publicidad institucional como una modalidad de aquella. Por este motivo, nos centraremos en el origen de la publicidad institucional como una modalidad de la comunicación pública. Para ello, partiremos de los autores Rolando (1990), Mancini (1996), Tornos \& Galán (2000), Cólera (1999) y Faccioli (2002). Se comenzará con la aportación de cada uno de estos autores para entender cómo llegan a identificar la comunicación pública en cuatro tipologías y cómo la publicidad institucional pertenece a una de ellas.

Mancini (1996), coincide con la tipología aportada por Rolando (1990), en la que diferencia la comunicación pública en cuatro tipologías: la comunicación política, comunicación social, comunicación institucional y la comunicación de otras instituciones. La comunicación política promovida por partidos políticos con intereses 
de índole político. La comunicación social gestionada por organizaciones públicas, privadas o semiprivadas que tienen como finalidad promover ideas controvertidas de interés general. La comunicación institucional de las Administraciones Públicas realizada por organismos públicos y cuyo contenido se relaciona directamente con su actividad. Y la comunicación de otras instituciones casi públicas sustentadas por instituciones privadas o semi-públicas, diferentes de las específicamente políticas, y que desarrollan una comunicación en torno a temas controvertidos, también de interés general, con el propósito de influir en la opinión de los ciudadanos como los sindicatos.

Por su parte, Tornos \& Galán (2000), como otros, identifican una tipología de comunicaciones públicas en cuatro tipos de comunicaciones: la comunicación jurídico-formal, la comunicación imagen, la comunicación de servicio y la comunicación administrativa. La comunicación jurídico-formal

... tiene como objetivo regular jurídicamente las relaciones entre los sujetos miembros del ordenamiento, en la medida en que les suministra certezas así como la cognoscibilidad de normas y actos (...), es decir, asegurar que los sujetos destinatarios efectivamente entren en conocimiento de la información suministrada se reduce simplemente al cumplimiento de un requisito formal (Tornos \& Galán, 2000, pp. 41-42).

La comunicación imagen recoge todas las actividades públicas que tienen como fin promover la imagen de la institución. Las estrategias y tácticas utilizadas provienen del mundo de la publicidad y de las relaciones públicas. La comunicación de servicio se refiere a la que tiene como objeto suministrar información sobre servicios por la Administración (turismo, espectáculos, tiempo...). Y la comunicación administrativa pretende convencer a los ciudadanos a que presten su colaboración a la Administración en aras de un interés público, también llamada administración compartida.

Por su parte, Cólera Leirado (1999) diferencia tres tipos de publicidad institucional: la campaña institucional regulada en los procesos electorales; la publicidad institucional en la que los Administraciones comunican sus logros y actuaciones y la información periódica institucional en la que se informa sobre la 
información de los servicios públicos (1999, 187 ss).

Mientras, Faccioli (2002) entiende que en la comunicación pública se pueden diferenciar dos áreas: una informativa y otra promocional. La función informativa se puede dividir a su vez en: comunicación normativa (la publicidad de las leyes, decretos, entre otros); comunicación institucional (la gestión de la Administración y comunicación formativa); y las actividades de formación dentro de las Administraciones. La función promocional se subdivide en: comunicación de utilidad pública-social (educación, defensa, cultura, entre otros) y la comunicación de la imagen nacional (cultura, productos, turismo).

De la aportación de estos autores se pueden identificar cuatro modalidades de la comunicación pública que son: la comunicación política, la comunicación administrativa/ legal, la comunicación informativa y la comunicación institucional/imagen (Martínez, 2009).

La comunicación política es promovida por los partidos y líderes políticos. La comunicación jurídicoformal o administrativa se refiere a la información que debe ser notificada a los interesados de forma individual o colectiva porque afecta a sus derechos o intereses. En otras palabras, dan cumplimiento de un requisito exigido por ley para la validez o eficacia de lo comunicado. Un ejemplo de estas comunicaciones son las publicaciones de normas, actos administrativos o resoluciones judiciales (Salerno, 2003). De igual modo, todo ciudadano que esté interesado en obtener información general sobre la Administración Pública tiene derecho a que la administración le ofrezca esta información sobre un procedimiento o sobre actos o disposiciones que le afecten individualmente (García Inda, 2002). La comunicación informativa es aquella que tiene como propósito hacer saber a los ciudadanos el funcionamiento, la gestión o los procedimientos de servicios públicos en aras del principio de transparencia entre la Administración y el ciudadano, sin tener la intención de persuadirlo, como por ejemplo, la información de interés general que es ajena a la administración como la meteorología, el turismo o los espectáculos (Tornos \& Galán, 2000). En el ámbito publicitario estos mensajes los denominamos publicidad informativa institucional. Mientras que la comunicación institucional, que se define como la relación entre poder público (la Administración) y el público, o los civiles (Faccioli, 2002), cuyas 
temáticas son de carácter jurídico, electoral, laboral, social, económico y cultural. Se entiende que la comunicación institucional e informativa son inseparables. Conjugamos en la publicidad institucional las dos comunicaciones porque todo mensaje tiene una carga informativa revestida de persuasión. En la publicidad institucional el mensaje es de tipo informativo porque es de interés general, pero al unísono, hay una intencionalidad persuasiva por parte del Estado anunciante, que la carga de subjetividad, es decir, de persuasión. Por este motivo, incluimos en la misma modalidad publicitaria: la institucional y la informativa caracterizada por una comunicación funcional (informa de las funciones y servicios de la Administración) y por una simbólica (crea su imagen de marca hacia sus ciudadanos, es decir, su imagen corporativa) (Mancini, 1996, p. 113). De manera que la publicidad institucional es una forma de comunicación pública (Moreu, 2005).

\section{Aproximación a la publicidad institucional}

El significado de la publicidad institucional está íntimamente relacionado con el desarrollo de la publicidad.
A partir de los años 70 del siglo XX surge una nueva forma publicitaria en el ámbito de la empresa, denominada publicidad institucional, cuya finalidad era la de promocionar la buena imagen de las empresas más allá de los productos o servicios que ofrecían (Moreu, 2005, pp. 56-57). Se construían mensajes de valores asociados a la marca anunciada. Esta iniciativa comienza a despertar interés por la Administración Pública. A partir de los años 80 se destaca un importante incremento de las campañas del Gobierno en los países occidentales (García López, 2001). Mientras que otros autores analizan la publicidad institucional desde una perspectiva social como Cortés González (2007) o García López (2001); otras investigaciones abordan la comunicación institucional frente al de Comunicación Corporativa como Sotelo Enríquez (2001), y otros estudios focalizan su atención en la comunicación de las administraciones con sus ciudadanos (Chías, 1995; Beato Espejo, 2003). La mayoría de los autores coinciden en que la publicidad institucional tiene dos objetivos al unísono: ofrecer información a sus ciudadanos y construir su propia imagen de marca de Gobierno gracias a la publicidad institucional, tal 
y como lo hacen las empresas privadas. Sin embargo, el uso y abuso de esta práctica por el Gobierno salta a la opinión pública y se cuestiona si este puede gastarse elevadas cantidades económicas en campañas publicitarias del erario público o si es una herramienta más de la propaganda política, que bajo la apariencia del interés general oculta una comunicación de "autobombo". Barbería sostiene que la publicidad institucional "venden los logros supuestos o reales de los Gobiernos bajo la coartada del interés del ciudadano" (Barbería, 2002), en donde es difícil saber "si estamos ante un anuncio del referente que se anuncia o frente a un anuncio del anunciador" (De Moragas, 2005, p. 73). De manera que "la publicidad se convierte en la corte ante cuyo público permite que se desarrolle el prestigio, y no la crítica en él" (Habermas, 1999, p. 227). Además, algunos consideran que esta publicidad ofrece al Gobierno la posibilidad de entrar en campaña antes del período electoral oficial impregnando de sus valores democráticos a los ciudadanos bajo la apariencia de información (Barbería, 2008), con un carácter marcadamente desleal frente a sus otros competidores políticos que tienen limitada esta posibilidad por ley.
Lo cierto es que estas controversias provocaron que el Gobierno de España, en aras de generar una transparencia Administrativa, promulgara en 2005 la Ley 29 de 29 de diciembre, de Publicidad y Comunicación Institucional (LPCI), cuya regulación se centra en esta modalidad publicitaria sufragada con el erario público, como a continuación se explica.

Sin embargo, antes de adentrarnos en el marco jurídico de esta modalidad conviene diferenciar la publicidad institucional de la comercial. La publicidad comercial en España está regulada por el artículo 2 de la Ley 34/1988 de 11 de noviembre, General de Publicidad (LGP). Este precepto dispone que se entiende por publicidad "toda forma de comunicación realizada por una persona física o jurídica, pública o privada, en el ejercicio de una actividad comercial, industrial, artesanal o profesional con el fin de promover de forma directa o indirecta la contratación de bienes muebles o inmuebles, servicios, derechos y obligaciones." Esto indica que la publicidad comercial se caracteriza principalmente por cinco elementos: la comunicación, el emisor, la actividad y el interés de quien la realiza y el destinatario (Alonso \& Lázaro, 2012; Martínez 2010). 
En primer lugar, la publicidad comercial es una forma de comunicación caracterizada por ser un mensaje cargado de persuasión, de carácter subjetivo. Además, tal y como apunta Alonso \& Lázaro (2012), la amplitud de la proposición legal "toda forma de comunicación" indica que esta modalidad publicitaria se vale de cualquier medio y soporte por la que se vehicule. En segundo lugar, el emisor es el anunciante, puede ser una persona física o jurídica, que idea realizar una campaña publicitaria en su beneficio. Se indica claramente la irrelevancia de forma o condición de la persona o personas que realizan la actividad publicitaria y su posible imputación a esta norma. Es decir, cualquiera pueda realizar un anuncio. En tercer lugar, los anunciantes son aquellos que realizan una actividad comercial, industrial o artesanal o profesional. Esto indica que son todos los trabajadores por cuenta propia o ajena. Pero al circunscribir la actividad al ámbito comercial, entendemos que la norma quedaría coja porque no dice nada respecto de otros tipos de mensajes publicitarios como la publicidad institucional, la social, la política o la electoral (Martínez 2010). De ahí la necesidad e importancia de la Ley relativa a la Publicidad Institucional que analizaremos a continuación y que delimita la naturaleza de esta modalidad publicitaria. En cuarto lugar, el interés es el motor que mueve al anunciante a realizar una determinada campaña publicitaria. Nadie idea un mensaje publicitario si con ello no obtiene un beneficio económico o de otra índole. Finalmente, en quinto lugar, la irrelevancia del destinatario del mensaje publicitario a los efectos de la aplicación de la LGP expresa al final del artículo 2 en relación a como se entenderá el destinatario (Alonso \& Lázaro, 2012). En cuyo caso parece que indique que se considera destinatario potencial o real, a diferencia de la publicidad institucional, cuyo destinatario siempre debe ser el ciudadano, ya sea para informarle, alertarle, prevenirle o protegerle.

Esto muestra que la LGP es una norma que recoge el concepto legal de publicidad de forma parcial y, por ello, cada vez es más necesario normas que regulen cada una de las modalidades publicitarias como es el caso que nos ocupa con la Publicidad Institucional. A continuación, se analizará esta norma jurídica y se indicarán las peculiaridades de esta modalidad publicitaria, así como la inversión que ha tenido estos últimos años (2006-2012). 


\section{Marco jurídico de la Publicidad Institucional en España}

La Ley 29/2005 de 29 de diciembre, de Publicidad y Comunicación Institucional es una norma pionera porque define expresamente qué son las campañas institucionales de publicidad, delimita su naturaleza, identifica al sujeto anunciante (la Administración General del Estado y las demás entidades integradas del sector público estatal), y detalla las prohibiciones en esta modalidad, además de indicar las competencias atribuidas a la comisión de publicidad y comunicación institucional (Martínez, 2011).

Actualmente conviven en nuestro país la LPCI de carácter nacional y las normas autonómicas en materia de publicidad institucional. La LPCI tiene como ámbito de actuación todo el territorio nacional y las comunidades autónomas que no dispongan de una ley de publicidad institucional, como es el caso de Madrid. Nosotros nos centraremos solo en la norma estatal para analizar los sujetos, los mensajes y las limitaciones y prohibiciones.

La ley indica que solo pueden ser sujetos anunciantes las siguientes entidades, de acuerdo con la Ley 47/2003 de 26 de noviembre, General Presupuestarias (art. 2): la Administración central del Estado, los organismos autónomos dependientes de la Administración General del Estado, las entidades públicas empresariales, las entidades gestoras de la Seguridad Social, las sociedades mercantiles estatales, las fundaciones del sector público estatal, las entidades estatales de derecho público y los consorcios dotados de personalidad jurídica. En definitiva, las Administraciones General del Estado y las entidades del sector público (art. 1), como pueden ser las campañas del Ministerio de trabajo para prevenir los accidentes en el trabajo; de la Dirección General de Tráfico (DGT), que depende del Ministerio del Interior, para evitar accidentes de tráfico por conducir ebrio, por ejemplo, o las fundaciones del sector público estatal como la Fundación Víctimas de Terrorismo.

Los mensajes susceptibles de ser publicitados por la Administración Pública son los relativos a temas jurídicos, electoral, laboral, social, económico y cultural (art. 3.1.).

Los temas jurídicos con el objeto de promover, informar y difundir los valores y principios constitucionales, las disposiciones jurídicas de repercusión social. En materia electoral, las campañas de publicidad institucional deben informar a los ciudadanos sobre los procesos electorales. Los anuncios 
de temas laborales deben tener el propósito de informar y difundir a los ciudadanos ofertas de empleo público. En cuanto a los asuntos sociales, las campañas tienen que anunciar y advertir de la adopción de medidas y programas de actuación de seguridad pública, de riesgos o daños de cualquier naturaleza para la salud de las personas o del patrimonio nacional que sean de interés social. En asuntos económicos, la publicidad debe apoyar y promover la economía y los sectores económicos en el exterior, y en los temas culturales, la publicidad tiene que difundir la cultura española a través de la lengua, el patrimonio histórico y natural de España.

De manera que los mensajes susceptibles de ser publicitados por la Administración Pública se pueden categorizar en seis ejes: el jurídico, el electoral, el laboral, el social, el económico y el cultural (art. 3.1.LPCI).

a. El jurídico: promover, informar y difundir los valores y principios constitucionales, las disposiciones jurídicas de repercusión social. Véase a continuación un anuncio del Ministerio de igualdad que promueve el conocimiento de la Ley de Igualdad.

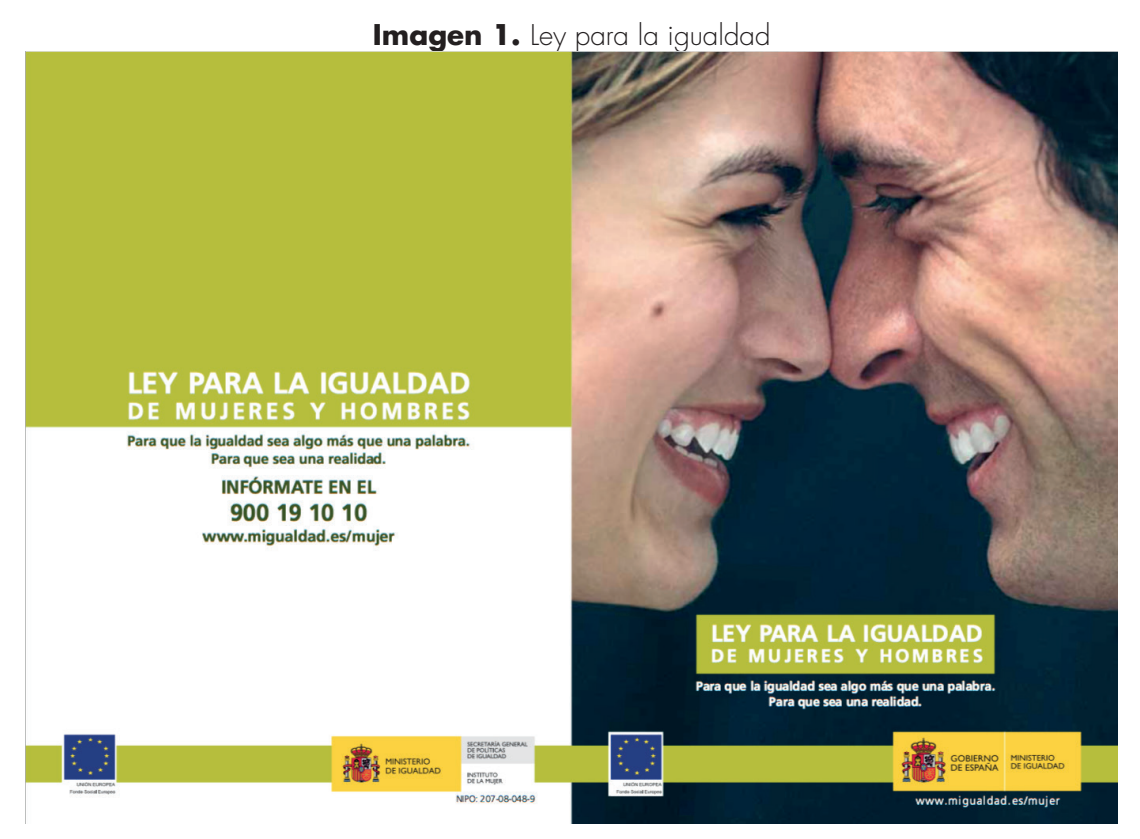

Fuente: http://www.inmujer.gob.es/areasTematicas/comunicacion/campanas/docs/ folletoCastleylgualdad2007.pdf 
b. El electoral: informar a los ciudadanos sobre los procesos electorales. Véase a continuación una campaña para informar del día de ejercer el voto para las elecciones autonómicas y municipales en 2015.

Imagen 2. ¿Cómo votar desde el extranjero?

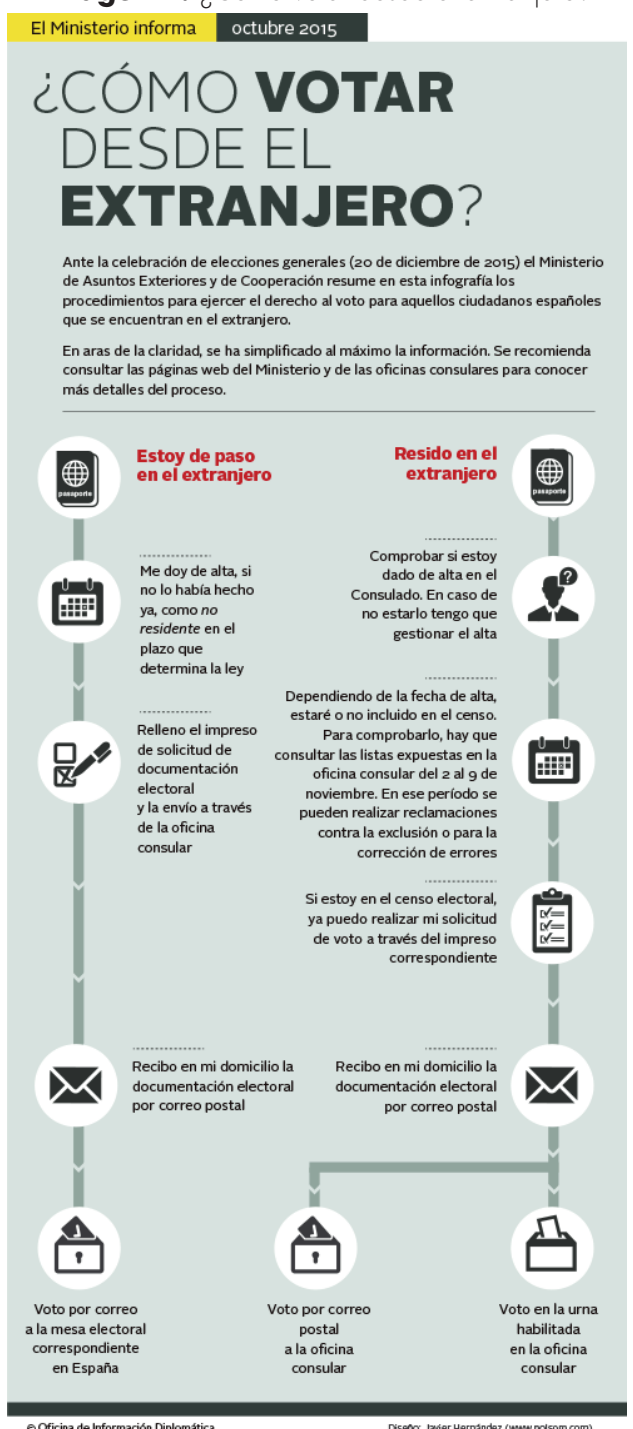

Ministerio de Asuntos Exteriores y de Cooperación Fuente: hitp: / /www.exteriores.gob.es/portal/es/ serviciosalciudadano/siestasenelextranjero/paginas/participaenlaselecciones.aspx 
c. El laboral: informar y difundir a los ciudadanos ofertas de empleo público. Véase a conti-

nuación un ejemplo.

Imagen 3. Plan de empleo municipal

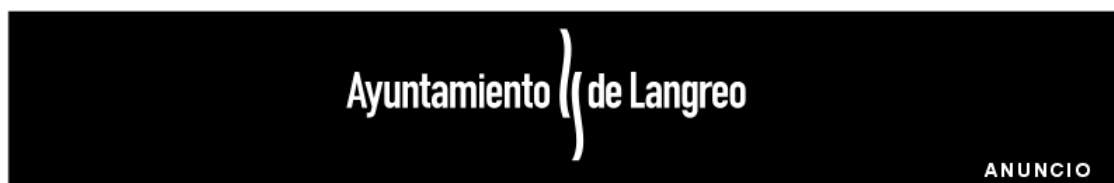

\section{PLAN DE EMPLEO MUNICIPAL 2012-2013}

Por la presente se abre la convocatoria pública para la contratación temporal durante doce meses de los puestos de trabajo que a continuación se relacionan.

$\mathbf{N}^{\circ}$ de puestos y CATEGORÍAS

\begin{tabular}{|l|l|}
\hline 3 & Técnicos de Turismo \\
\hline 3 & Oficiales de albañilería \\
\hline 2 & Oficiales eléctricos \\
\hline 1 & Oficial pintor \\
\hline 1 & Oficial fontanero \\
\hline 1 & Oficial jardinero \\
\hline 30 & Peones \\
\hline
\end{tabular}

Requisitos Generales:

- Estar empadronado en Langreo con una antigüedad ininterrumpida de un año.

- Estar desempleados e inscrito en el Servicio Público de Empleo con una antigüedad ininterrumpida de seis meses.

- No haber trabajador en los últimos seis meses

- Que todos los miembros de la unidad familiar o de convivencia se encuentren desempleados

- Que los ingresos no superen los módulos establecidos en las bases

Para los Oficiales:

- Tener experiencia profesional relacionada con la plaza que se solicita

Para los técnicos de turismo:

- Tener la diplomatura de Turismo o Grado Superior en Información y Comercialización Turística.

- Estar en posesión de un título oficial de Ingles con nivel de competencia B2 o superior.

SOLO SE PODRÁ OPTAR A UNA PLAZA

Lugar de recogida de bases y solicitudes: Oficina de Información situada en la planta baja de "Casa Cuca". Página web municipal www.langreo.as

Plazo y lugar de presentación de instancias: Del día 2 al 13 de julio(ambos inclusive) Registro General situado en "Casa Cuca" de 9,00 a 14,00 h.

En Langreo, a 26 de junio de 2012. LA ALCALDESA. Fdo: María Fernández Alvarez

Fuente: hitps://lanapublicidad. files.wordpress.com/2012/06/anuncio-ayło.png

d. El social: anunciar y advertir de la adopción de medidas y programas de actuación de seguridad pública, de riesgos o daños de cualquier naturaleza para la salud de las personas o del patrimonio nacional que sean de interés social. Véase a continuación una campaña. 
Imagen 4. Ante el maltratador, tolerancia cero

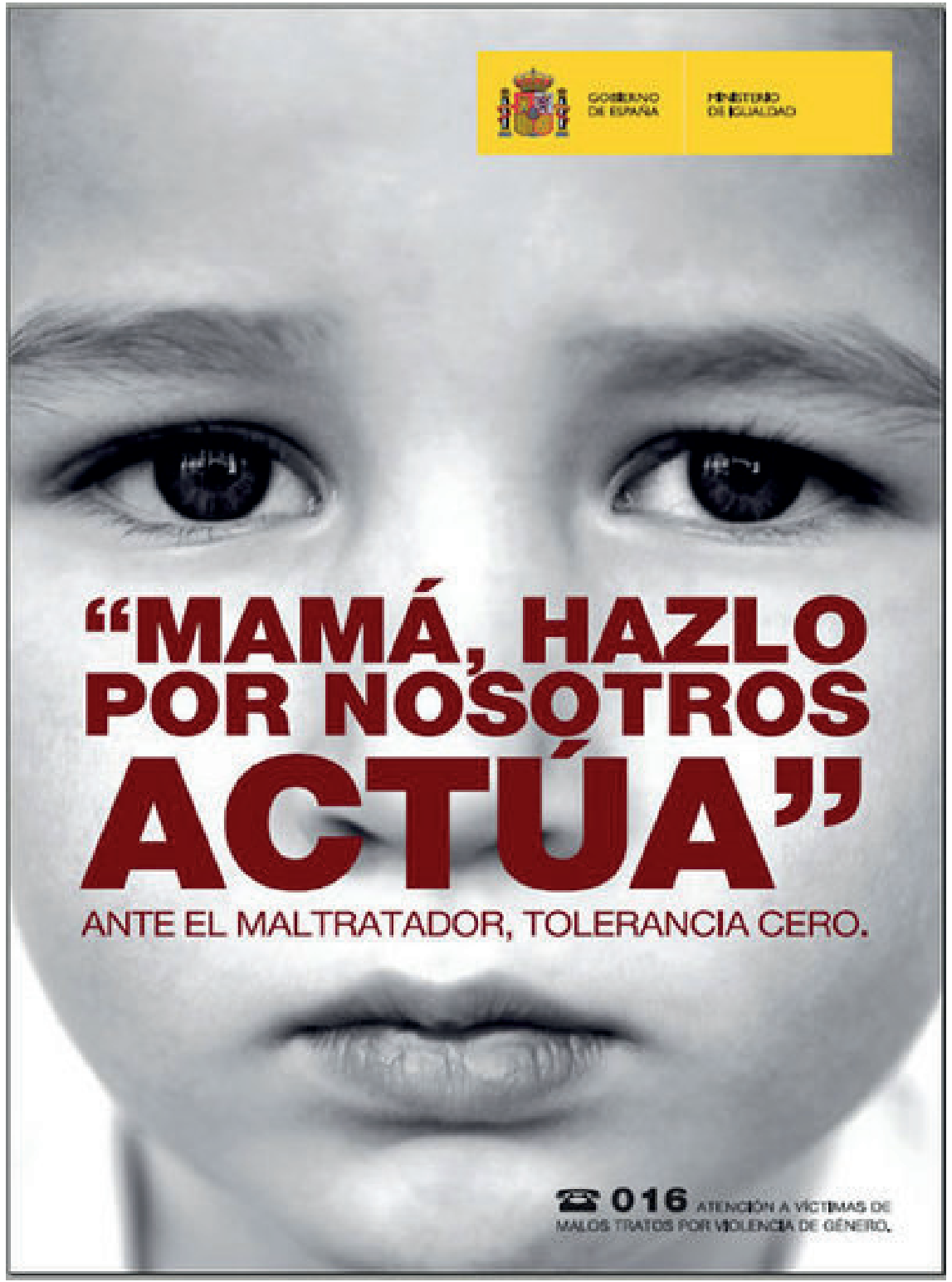

Fuente: http://sociedad.elpais.com/sociedad/2008/07/08/actualidad/1215468005_850215.html

e. El económico: apoyar y promover la economía y los sectores económicos en el exterior.
En este caso, se muestra una campaña para ahorrar energía 
y pensar en el futuro económico de España.

f. El cultural: difundir la cultura española a través de la lengua, el patrimonio histórico y natural de España. A continuación se muestra un anuncio de la Universidad Nacional a Distancia (UNED) para promocionar la cultura y la formación dentro y fuera de España a distancia.

De la misma manera, la ley expresa las prohibiciones de las campañas de publicidad institucional. Estas nunca pueden destacar los logros de la entidad pública (de carácter de autobombo, como se mencionó anteriormente); menoscabar las políticas públicas; discriminar por ser sexistas o contrarias a los principios, valores o derechos constitucionales; incitar a la violencia; atentar contra el ordenamiento jurídico; inducir a error con los símbolos, ideas, expresiones, diseños o imágenes y realizar campañas institucionales en periodo electoral y durante el referéndum. Y quedan excluidas de la modalidad de la publicidad institucional las campañas de carácter comercial y legal. Por otra parte, la ley incluye tipos de comunicación como promociones, relaciones públicas y otras herramientas comunicacionales que no son propiamente publicitarias, asunto que debería cuestionarse por no ajustarse al objeto regulado que es publicidad institucional.

\section{Campañas de Publicidad Institucional del Estado español realizadas durante 2006-2014}

Las campañas del Estado español reguladas por la LPCI y ajustadas a esta norma vigente comienzan a partir de 2006, por este motivo, nuestro análisis se centra en 2006-2012. Las campañas realizadas por el Estado, como se ha dicho anteriormente, se circunscriben, a los Ministerios y organismos dependientes de estos; conviene indicar que en 2008 se excluyeron las campañas de Turespaña, Renfe operadora y en 2010, las del Instituto Nacional de las Artes Escénicas y de la Música (INAEM) por ser consideradas comerciales. Por ello, haremos alusión a ellas en los años que son consideradas institucionales.

La LPCI especifica que cada año los Ministerios y organismos dependientes debe realizar un Plan de publicidad (art. 12) y un Informe (art. 14) de la Publicidad institucional para responder al principio de transparencia. En el caso del Plan, este será 
aprobado por el Consejo de Ministros durante el mes de enero de cada ejercicio. En el Plan se deben detallar todas las campañas institucionales que prevean desarrollar indicando el objetivo, coste previsible, período de ejecución, herramientas de comunicación utilizadas, sentido de los mensajes, destinatarios, organismos y entidades afectadas. Mientras que el Informe se realiza después de realizar las campañas de publicidad institucional. En este se detallan todas las campañas institucionales llevadas a cabo junto con el importe, los adjudicatarios de los contratos celebrados y los planes de medios correspondientes. Este informe debe ser aprobado por el Consejo de Ministros y de las Cortes Generales, y debe ser públicamente expuesto para que quede a disposición de todas las organizaciones profesionales del sector y de los interesados. En este estudio nos limitaremos al análisis de los Informes una vez que las campañas se han difundido en medios de comunicación en 2006-2012.

De acuerdo con los datos del Plan de la Publicidad Institucional facilitados por la Comisión de Publicidad y Comunicación Institucional (2013) se analizará en este estudio: la inversión de la publicidad institucional; el número de campañas difundidas; las campañas en las que se invierten más de 2 millones de euros y los medios de comunicación en las que se difunden las campañas de publicidad institucional realizadas en 2006-2012.

\section{La inversión de la publicidad institucional en euros}

La inversión de la publicidad institucional desde 2005 ha descendido progresivamente por la crisis económica que ha acaecido en España. Así, se observa que en 2006 se invirtió 209.767.393 de euros; en 2007 aumentó a 269.523.547, y desde 2008 empieza el descenso de inversión de 134.515.104 de euros para pasar en 2009 a 95.293.027 de euros, en 2010 a 80.832 .130 de euros, en 2011 a 67.401 .193 a euros y en 2012 a 19.807.113 de euros. Esto muestra una variación porcentual de inversión desde 2006 de $-67,8 \%$. Lo que deja claro que la inversión de publicidad institucional ha disminuido en la mitad del presupuesto en 2007, que es su punto más alto de inversión (Comisión de Publicidad y Comunicación Institucional, 2013), véase Gráfica 1. Si estos se cruzan con los datos del PIB, se observaría que el ascenso de 
la inversión corre en paralelo con la situación económica de nuestro país.

Gráfica 1. Inversión en Campañas de Publicidad Institucional (2006-20 12 )

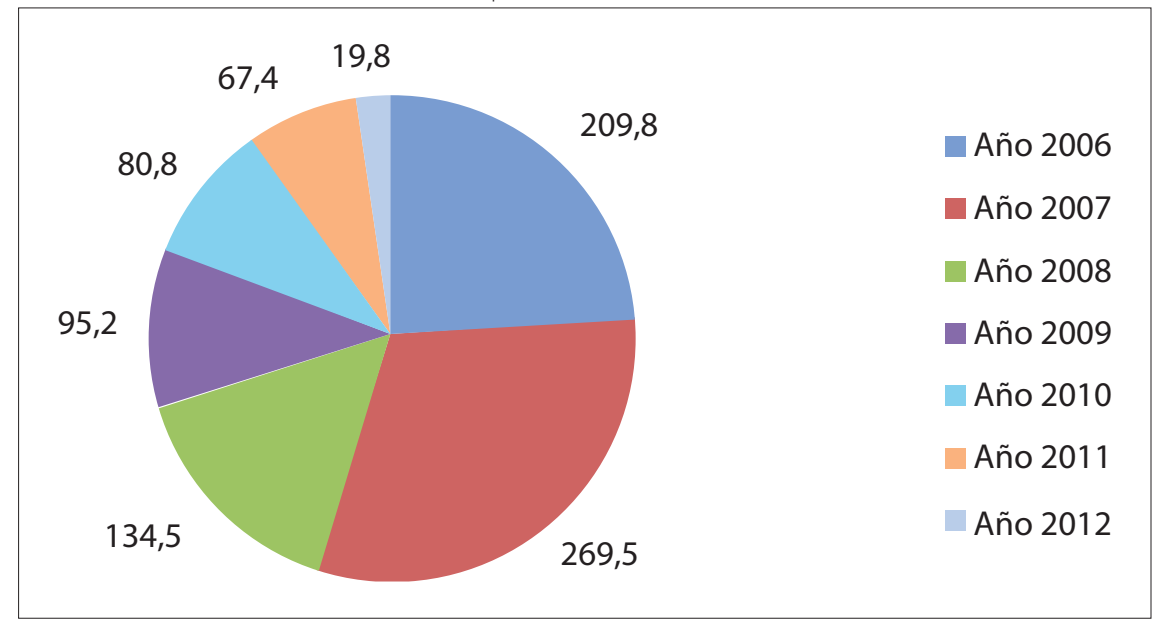

Elaboración propia a partir de los datos de Comisión de Publicidad y Comunicación Institucional, 2013.

\section{El número de campañas de} publicidad institucional realizadas y su evolución de 2006-2012

En cuanto al número de campañas institucionales en relación con la inversión, el número de campañas realizadas también disminuye desde 2006. En 2006 se realizan 214 y progresivamente en los años sucesivos disminuyen a 188 (2007), 176 (2008), 139 (2009), 127 (2010), 152 (2011), y el número menor es de 2012 con tal solo 45 campañas: véase Gráfica 2. Las campañas institucionales que se contratan pueden incluir la creatividad de la pieza, la compra de medio y, en ocasiones, el pretest de la campaña. La mayoría de las veces se compra la creatividad y la compra de medios y en menos ocasiones el pretest, ya que esto incrementa el precio final. En los últimos años, debido a la crisis, los Ministerios adquieren los espacios en medios y utilizan la creatividad adquirida otros años. Es decir, difunden las mismas campañas de publicidad realizadas en años anteriores. 
Gráfica 2. Número de Campañas de Publicidad Institucional (2006-20 12 )

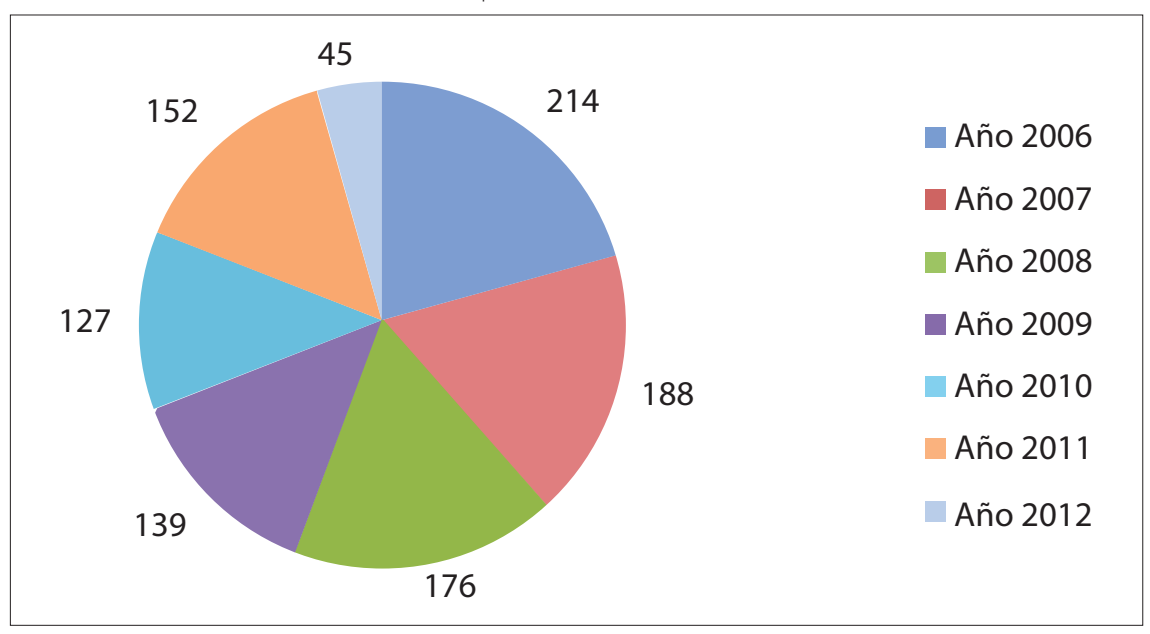

Elaboración propia a partir de los datos de Comisión de Publicidad y Comunicación Institucional, 2013.

\section{Las campañas en las que se invierten más de 2 millones de euros}

Los años en los que se ha invertido más de dos millones de euros en campañas de publicidad institucional han sido en 2007, con 43 campañas, $y$ en 2008, con 21. Mientras que en 2012 solo hay 2 campañas. Conviene indicar que en los Informes se computa como una campaña de más de 2 millones de euros cuando en realidad el Ministerio hace una contratación anual a una agencia de publicidad, pero esta realiza durante el año numerosas campañas. Este es el caso del Ministerio de Interior, la DGT o el Ministerio de Medio Ambiente, en los años indicados 2006, 2007 y 2008. Sin embargo, creemos necesario indicarlo aunque no se especifique en los datos facilitados por el Ministerio de Presidencia: véase Gráfica 3. 
Gráfica 3. Campañas en las que se invierten más de 2 millones de Euros (2006-2012)

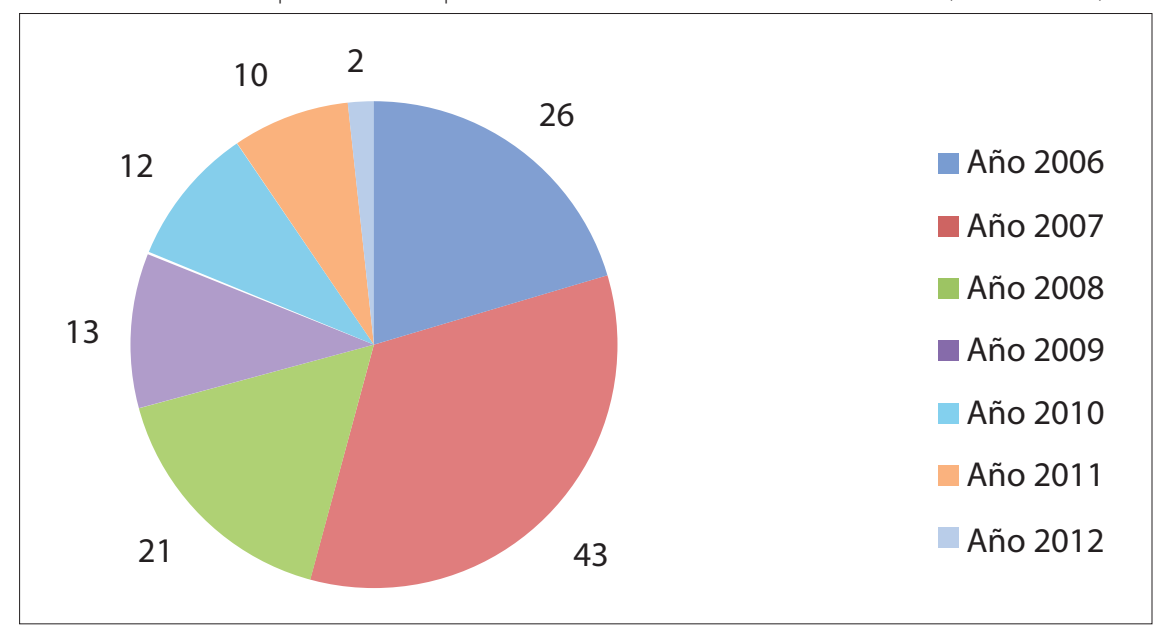

Elaboración propia a partir de los datos de Comisión de Publicidad y Comunicación Institucional, 2013.

De aquí conviene indicar que las campañas que tienen una inversión superior a los 2 millones de euros tienen un claro interés público como es el caso de la DGT (organismo dependiente del Ministerio de Interior), y del Ministerio de Medio Ambiente en cuanto a la prevención y concienciación de la sociedad de temas relativos a sus Ministerios. Nos detendremos en la DGT como organismo para mostrar la importancia y justificación de esta publicidad.

En el caso de la DGT es un organismo que anualmente realiza una única contratación publicitaria a una sola agencia de publicidad, la cual debe desarrollar todas las campañas tanto de prevención, como de concienciación y de información.
De forma pública y transparente se convoca el pliego de condiciones de contratación para que se presenten las agencias de publicidad interesadas en desarrollar las campañas. La DGT tiene unas líneas prioritarias en materia de seguridad vial que derivan de sus propios estudios e investigaciones anuales, de las obligaciones legales nacionales y comunitarias, así como de las líneas que quiera desarrollarse por el interés general en nuestra sociedad. El tipo de mensaje de las campañas de publicidad de la DGT son de carácter preventivo, testimonial e informativo.

Las campañas que se repiten cada año son las relativas a evitar la siniestralidad en carretera por el alcohol y la velocidad. Siempre hay tres oleadas 
de campañas en Navidades, Semana Santa y verano, en las que se realizan campañas en relación a estos asuntos indicados, alcohol y la velocidad. De igual manera, son frecuentes las líneas de actuación respecto a:

- grandes vehículos, camiones, en relación con las cadenas y el correcto estado de los vehículos;

- la conducción de las motocicletas y la utilización del casco;

- los peatones y el respeto a los semáforos y ceda el paso;

- y medidas de seguridad en el vehículo como cinturón, sillitas para los niños, etc.

- los ciclistas como parte de la conducción vial.

Las campañas de publicidad con estos objetivos se difunden en momentos concretos.

Por ejemplo, en invierno se realizan diferentes oleadas para prevenir del frío y hielo, y recordar a los camioneros del uso de cadenas en la carretera o se lanzan campañas a las madres (público objetivo de las campañas de la DGT por llevar habitualmente a los niños al colegio) durante el curso escolar para la utilización de dispositivos de seguridad, las sillitas en el coche, para los menores.
Esto indica que el target al que se dirigen las campañas es muy variado porque abarca: niños, adolescentes, jóvenes y adultos. Es decir, a toda la población que activamente, conduciendo, o pasivamente, peatones, participan en la vía pública.

Son campañas preventivas, testimoniales e informativas pero también tienen identificado cada uno de sus target dependiendo del objeto de concienciación. De hecho, el público objetivo representado es muy amplio, ya que se muestran a conductores en general, a familias, conductores jóvenes en motocicletas, a conductores de camiones, a ciclistas, a madres, a padres en contextos cotidianos para que cada ciudadano pueda sentirse identificado. El objetivo de las campañas se ajusta a cada problemática que se quiere abordar, y dependiendo de las líneas de la DGT o de las directrices que a nivel europeo quieren prevenirse, se aborda un tema u otro cada año.

Se deduce que son campañas de publicidad claramente de interés general, cuya repercusión se lleva a cabo mediante la repetición y cuya eficacia en la mayoría de los casos es difícil de cuantificar, dado que confluyen muchas variables que dificultan medir 
los resultados de las campañas, como por ejemplo la meteorología.

En el caso de la DGT, las campañas de publicidad el medio en el que más se emiten y difunden estas campañas son en radio. La gran mayoría de campañas se llevan a cabo utilizando la radio, porque es el medio que se escucha mientras que se conduce y donde se localiza al destinatario de las campañas. Sin embargo, la mayoría de las campañas se difunden por los medios de comunicación tradicionales, televisión, prensa y radio; por los medios específicamente publicitarios como son las vallas o el mobiliario urbano (Pacheco, 2000); y en los últimos años se está incorporando el soporte digital como a través del formato de los banners en los sites o webs.

Esta es una aproximación a uno de los organismos en los que más se invierte en publicidad institucional, cada ministerio tiene unas líneas y objetivos que podría ser objeto de otro estudio.

\section{Medios de comunicación en los que se difunden las campañas de publicidad institucional}

Durante el lapso de tiempo analizado, de 2006 a 2012, el medio estrella en el que más se invierte es en televisión, con una inversión total de 366.862.710 euros, seguido de la prensa con un total de 235.231 .318 euros, y de la radio con una inversión de 127.862.961 euros. El medio en el que menos se invierte es en el cine, $\tan$ solo con 2.080.080 euros y queda a la par Internet y las vallas publicitarias (60.597.914 y 67.039.273 respectivamente). Llama la atención que se invierta tan poco en Internet y que descienda la inversión en el cine. De otra parte, entendemos que la televisión, la prensa y la radio sean los medios preferidos por las Administraciones Públicas, porque es donde se concentra mayor número de ciudadanos. De los datos obtenidos, conviene indicar que en $2006 \mathrm{y}$ 2007 la inversión de revistas se computa en prensa, y que en el cine los mismos años se computan en otras herramientas. En estas acciones de comunicación, "otras herramientas" también se incluyen acciones que no son propiamente publicitarias y deberían indicarse claramente cuáles son.

\section{Conclusiones}

La publicidad institucional es una potente herramienta de comunicación pública al servicio de las Administraciones Públicas y organismos 
dependientes, cuyo propósito es informar y comunicar a los ciudadanos sobre cuestiones de interés público y general.

Por su naturaleza pública, esta debe velar por una adecuada publicidad institucional que responda a los objetivos generales de sus ciudadanos y ser transparente de cara a todos los ciudadanos que son los que sufragan esta publicidad, evitando los posibles autobombos de los Gobiernos de turno y de "autopromoción" de los partidos políticos. Esto justifica la necesidad de la promulgación de la ley que anteriormente hemos descrito y de la aprobación del Plan de la Publicidad Institucional y un Informe antes y después de la difusión de las campañas de publicidad institucional. Lo que se deja claro de los datos obtenidos de la Comisión de Publicidad y Comunicación Institucional (2013) es que la inversión de publicidad institucional está al unísono con la economía del país. De hecho, el mayor número de campañas realizadas fueron durante 2006 y 2007, cuando había un Producto Interior Bruto del 4,1 y 3,5 respectivamente (PIB). Mientras que desde 2009 hay un claro descenso de nuestra economía, un -3,7, en 2010 un -0,1, en 2011 un 0,7 , y en 2012 un $-0,5$, estos datos corren en paralelo con la inversión publicitaria. Así vemos cómo en 2006 y 2007 se realizaron respectivamente 214 y 188 campañas numerosas en diferentes idiomas oficiales de España y extranjeros, atendiendo a una población muy diversa debido al gran flujo de inmigración, frente al 2010, 2011 y 2012 en los que se realizaron respectivamente 127, 152 y 45 campañas. De igual modo, el número de campañas de publicidad institucional que superan los 2 millones de euros son en 2006 (26) y en 2007 (43). Mientras que desde 2009 la inversión y el número de campañas desciende hasta llegar tan solo a 45 campañas en 2012. Conviene indicar que los Ministerios que suelen hacer más campañas son el Ministerio de Fomento, Ministerio de Interior, en especial la Dirección General de Tráfico (DGT), el Ministerio de Sanidad, Ministerio de Industria, Comercio y Turismo y el Ministerio de Medio Ambiente, Rural y Marino, respondiendo al tipo de información de interés público y general como es tráfico, enfermedades, salud o alimentación.

En cuanto a los medios de difusión preferidos para difundir los mensajes publicitarios, la televisión, la prensa y la radio son los más utilizados frente a las revistas, Internet 
o las vallas publicitarias. Se entiende que en los medios tradicionales se invierta más, puesto que la gran parte de la ciudadanía accede a la televisión, prensa o la radio. En especial, hay organismos que de forma premeditada prefieren un medio frente a otros. Este es el caso de la DGT que invierte más en radio que en otros medios, dado que su público objetivo mayoritario son los conductores, y el mejor lugar para captar su atención es durante la conducción, cuando se suele escuchar la radio. Resulta extraño la poca inversión en la red, aunque se entiende que esta irá in crescendo, así como se entiende que el cine tenga menor inversión en publicidad institucional que el resto de medios, dado que, en general, se suele invertir menos publicidad en este medio que en otros, tal y como se indica en los datos del "Estudio InfoAdex de la Inversión Publicitaria en España 2015”.

Esto nos muestra una radiografía de qué es y cómo está evolucionando la publicidad institucional en España, e igualmente, de la implicación de las Administraciones Públicas en este tipo de modalidad publicitaria de acuerdo con la normativa vigente creada ad hoc. Así como conviene seguir estudiando esta publicidad, dado que es de interés público y debe cumplir con el principal principio jurídico que es la transparencia, características que la hacen diferente a otros tipos de publicidad como es la publicidad comercial o la propaganda política.

\section{Referencias}

Alonso, F.J. \& Lázaro, E.J. (2012). “Nociones jurídicas básicas. Derecho de la Publicidad. En Lázaro, E. (Coord). Derecho de la publicidad. Navarra: Thonson Reuters, pp-47-64.

Barbería, J. L. (2008). “¿Una campaña encubierta con el dinero de todos?”. El País, 5 de Marzo.

Beato Espejo, M. (2003). Cauces de comunicación de las administraciones públicas con los ciudadanos. Madrid: Técnos.

Chías, J. (1995). Marketing Público. Por un Gobierno y una Administración al servicio del Público. Madrid: McGraw-Hill

Cólera Leirado, J. R., (1999). La actividad institucional de los poderes públicos en el período electoral. Corts. Anuario de Derecho Parlamentario, (8), 187-209. 
Comisión de Publicidad y Comunicación Institucional http://www.lamoncloa.gob.es/serviciosdeprensa/ cpci/Paginas/index.aspx

Cortes González, A. (2007). Cultura De paz y publicidad institucional. El estado en el fomento de la cultura de paz a través de la publicidad televisiva. Jaén: Alcalá Grupo Editorial.

De Moragas Spà, M. (2005). "Publicidad institucional: comunicación y civismo". Los monográficos B.M.M., (6).

Faccioli, F. (2002). Comunicazione pubblica e cultura del servizio. Roma. Carocci.

García Inda, A. (2002). "Régimen jurídico de la actividad publicitaria de las Administraciones Públicas", en Autocontrol de la publicidad, (69).

García López, M. (2001). Publicidad Institucional: El Estado Anunciante. Málaga: Universidad de Málaga.

La Ley 29/2005, de 29 de diciembre, de Publicidad y comunicación institucional (LPCI).

Infoadex (2015). Estudio InfoAdex de la Inversión Publicitaria en España 2015. Recuperado de: http://www.felixcaso.
es/wp-content/uploads/2015/02/NOTA-DE-PRENSA-infoadex.pdf

Lippmann, W. (2003). La opinión pública. Madrid: Langre.

Mancini, P. (1996). Manuale di comunicazione púbblica. Roma: Laterza Martínez, E. (2010). Los mensajes publicitarios analizados desde la comunicación y el derecho. Madrid: Universitas.

Martínez, E. (2012). Publicidad Institucional de las Administraciones Públicas: marco jurídico y controversias. En Comunicación y Hombre, (8), 51-63.

Moreu, E. (2005). La administración anunciante: régimen jurídico de la publicidad institucional. Navarra: Aranzadi.

Pacheco, M. (2000). Cuatro décadas de publicidad exterior en España. Madrid: Editorial Ciencias Sociales.

Planes e Informes de Publicidad y Comunicación Institucional. Recuperado de: http://www.lamoncloa. gob.es/serviciosdeprensa/cpci/Paginas/PlanesEInformes.aspx 
Rolando, S. (1990). Lo stato della pub- Sotelo Enríquez, C. (2001). Introducblicitá di Stato. Milano: Il Sole 24 ore. ción a la comunicación institucional. Barcelona: Ariel.

Rolando, S. (1995). La comunicazione pubblica in Itália. Milán: Editrice bibliográfica.

Tornos Mas, J. \& Galán Galán, A. (coords.) (2000). Comunicación pú-

Salerno, A. (2003). El régimen jurídiblica. La información administrativa al ciudadano. Madrid: Marcial Pons. co de la publicidad institucional de las administraciones públicas. Tesis doctoral. Madrid: Universidad complutense de Madrid. 